\title{
ENVOLVIMENTO PATERNO NA RELAÇÃO MÃE-BEBÊE: REVISÃO INTEGRATIVA DA LITERATURA
}

FATHERS' INVOLVEMENT IN THE MOTHER-CHILD RELATIONSHIP: AN INTEGRATIVE REVIEW OF THE LITERATURE

PARTICIPACIÓN PATERNA EN LA RELACIÓN MADRE-HIJO: REVISIÓN INTEGRADORA DE LA LITERATURA

\author{
Marina de S. Lopes Menezes* \\ Fabio Scorsolini-Comin ** \\ Tales Vilela Santeiro ${ }^{* * *}$
}

\begin{abstract}
RESUMO
O envolvimento paterno no desenvolvimento dos filhos tem cada vez mais despertado a atenção de estudiosos sobre família. O objetivo deste estudo é apresentar uma revisão integrativa da literatura científica, para identificar qual a relevância do envolvimento paterno para a relação mãe-bebê desde a gestação, e outras variáveis relacionadas a essa dinâmica familiar. Foi realizada uma consulta às bases de dados Lilacs, Pepsic e Scielo, sendo recuperados 15 artigos publicados entre janeiro de 2004 e dezembro de 2015. As evidências têm reforçado a importância da presença paterna como integrante da rede de apoio à mulher na gestação, parto e puerpério, e para estabelecimento dos vínculos entre pai e bebê/criança, fortalecimento da paternidade, promoção da saúde mental do filho e bem-estar da mulher. Esse tipo de achado ressalta a relevância e a necessidade de o pai repensar e discutir sua identidade social e familiar, com vistas a uma participação mais ativa no exercício da paternidade.
\end{abstract}

Palavras-chave: Relações familiares. Parentalidade. Paternidade. Produção científica.

\section{ABSTRACT}

Fathers' involvement in children's development has increasingly called the attention of those studying the family. The objective of this study is to introduce an integrative review of scientific literature, identify which is the

\footnotetext{
Texto recebido em 4 de janeiro de 2016 e aprovado para publicação em 30 de setembro de 2016.

*Graduanda em Psicologia pela Universidade Federal do Triângulo Mineiro (UFTM). E-mail: marina.slm@hotmail.com.

** Professor adjunto no Departamento de Psicologia, professor permanente e coordenador do Programa de Pós-Graduação (Mestrado) em Psicologia da UFTM. E-mail: fabioscorsolini@gmail.com.

"** Doutor em Psicologia pela Pontifícia Universidade Católica de Campinas (PUC Campinas), professor adjunto no Departamento de Psicologia e do Programa de Pós-Graduação em Psicologia da UFTM. E-mail: talesanteiro@hotmail.com.

Endereço de correspondência: Programa de Pós-graduação em Psicologia da Universidade Federal do Triângulo Mineiro, Rua Conde de Prados, 155 - Abadia, Uberaba-MG, Brasil. CEP: 38025-260.
} 
relevance of fathers' involvement in the mother-baby relationship since the gestation, and other variables related to this family dynamics. The databases Lilacs, Pepsic and Scielo were investigated, from which 15 articles published between January 2004 and December 2015 were selected. The evidences strengthen the importance of fathers' presence as members of the support network for women during pregnancy, delivery and puerperium, and for the establishment of the bonds between father and baby/child, enhancing paternity, the improvement of the child's mental health and the women's welfare. This type of finding outstands the importance and necessity that fathers overlook and discuss their social and family identity, viewing a more active participation in the exercise of parenthood.

Keywords: Family relationships. Parenting. Paternity. Scientific production.

\section{RESUMEN}

La participación paternal en el desarrollo de sus hijos ha despertado cada vez más la atención de los estudiosos sobre la institución familiar. El objetivo del estudio fue presentar una revisión de la literatura integradora, para identificar cual es la relevancia del envolvimiento del padre para con la relación madre-bebé, desde la gestación, y otras variables relacionadas a esta dinámica. Ha sido realizada una búsqueda en las bases de datos de Lilacs, Pepsic y Scielo, rescatando 15 artículos que han sido publicados entre enero de 2004 y diciembre de 2015. Las evidencias refuerzan la importancia de la presencia paternal como integrante de la red que apoya la mujer en la gestación, parto y puerperio, y también para el establecimiento del enlace entre padre y bebé/niño, fortificación de la paternidad, promoción de la salud mental del hijo y bienestar de la mujer. Este tipo de hallazgo pone de relieve la importancia y la necesidad del padre repensar y discutir su identidad social y familiar, con miras a una participación más activa en el ejercicio de la paternidad.

Palabras clave: Relación familiar. Crianza de los hijos. Paternidad. Producción científica.

\section{INTRODUÇÃO}

ada vez mais, a parentalidade vem sendo investigada como fenômeno
que destaca não apenas as funções da maternidade e da paternidade, mas
das representaçóes construídas social e culturalmente, e que atravessam
a constituição dos sujeitos bem como interferem nas práticas de educação e
cuidado. Tem havido certo consenso na literatura científica de que a parentalidade
deve ser compreendida de maneira dinâmica, contemplando aspectos macro e
microssistêmicos, atravessados por uma matriz histórica e social (Osório, 2013; 
Staudt \& Wagner, 2008; Walsh, 2016).

Nesse movimento constante que estrutura o conceito de parentalidade, observa-se que a família ocupa papel de destaque, ao acolher e corporificar diversas transformaçôes ao longo do tempo, as quais incidem sobre os modos de ser pai e mãe na Contemporaneidade, seus papéis, representações, desafios e potencialidades para o desenvolvimento humano (Benítez \& Cárdenas, 2010; Campos, 2012; Capitão \& Romaro, 2012; Falceto \& Waldemar, 2013; Gorin, Mello, Machado, \& Féres-Carneiro, 2015; Walsh, 2016).

As mudanças na esfera familiar espelham, de certa forma, um contexto social e cultural de questionamentos em torno do ser mulher e do ser homem. Uma das variáveis que influenciaram diretamente nesse cenário foi a mudança dos papéis femininos, que, por sua vez, acarretou em alterações dos masculinos, ampliando repercussões no exercício da parentalidade.

Salienta-se o contexto que favoreceu essa transfiguração, com a mulher em busca de sua autonomia e liberdade, desvinculando-a da estrita esfera doméstica. A inserção da mulher no mercado de trabalho é uma das consequências da insurgência do movimento feminista, que foi significativa para compreenderemse as mudanças sociais e familiares em voga (Benítez \& Cárdenas, 2010; Campos, 2012; Neves, 2013; Staudt \& Wagner, 2008).

A partir dessas movimentações sócio-históricas, o predomínio de produções relacionadas à maternidade passou a compartilhar espaço com investigações que destacam a categoria paternidade, especialmente nos últimos anos (Piccinini, Levandowski, Gomes, Lindenmeyer, \& Lopes, 2009). O maior interesse pela paternidade, no entanto, não ocorre de modo automático e apenas como forma de contrapor-se a uma tendência de investimento na figura materna e na sua relação com os filhos, porém se apresenta em meio a um cenário no qual se observa aumento no número de divórcios, redefinição de papéis sexuais, discussões em torno da demarcação dos papéis de homens e mulheres, e reflexões em torno da constituição familiar (Bossardi \& Vieira, 2010; Falceto \& Waldemar, 2013).

Estudos sobre envolvimento paterno têm indicado que a relação pai-bebê durante a gestação é estruturante da relação pai-filho após o nascimento, sendo importante compreender essa díade em uma perspectiva que valoriza a paternidade e seus contornos na Contemporaneidade (Garfield, 2015; Gomes \& Resende, 2004; McGill, 2014; Piccinini et al., 2009). Para Lamb, Pleck, Charnov e Levine (1985), três elementos devem ser considerados na avaliação do envolvimento paterno: interação, acessibilidade e responsabilidade. Utilizando esse modelo como referência, Bossardi e Vieira (2010) apresentam a necessidade de se observar e compreender como o pai se envolve nas atividades de cuidados 
para com o filho, sua disponibilidade física e emocional para esse contato e sua responsabilidade na garantia de cuidados e recursos para a criança.

A literatura tem assinalado, ainda, que o exercício e a expressão da paternidade têm ocorrido de modo mais participativo na Contemporaneidade, possibilitando a emergência de uma figura paterna menos distanciada das necessidades do filho e da família, com maior atenção a aspectos que ultrapassam a provisão de recursos financeiros e materiais. Esse pai traz em seu bojo, portanto, melhores condições para expressar sua afetividade. Por essa via, ele pode estabelecer interaçôes mais significativas e próximas, em uma perspectiva que se contrapóe à figura do chamado pai tradicional, marcado pelo distanciamento (Campos, 2012; Gomes \& Resende, 2004; Staudt \& Wagner, 2008).

Essa maior aproximação do pai em relação ao universo familiar e com maiores possibilidades de interação com os filhos ocorre em meio a desafios, posto que as tarefas de cuidado aparecem mais associadas ao papel da mãe, tendendo tornar o pai um coadjuvante desse processo. Logo, essa maior participação deve ocorrer a partir de uma transição, incentivando e contribuindo para o desenvolvimento do papel paterno (Bossardi \& Vieira, 2010; McGill, 2014; Vieira et al., 2014). No entanto, há de se considerar que mãe e pai ocupam importantes papéis e funçōes no desenvolvimento dos filhos e que existem diferenças que podem ser delimitadas com base em modelos familiares em vigência e de aspectos sociais e culturais presentes nessas configuraçōes (Bossardi \& Vieira, 2010).

A transição para a paternidade ocorre desde a gestação, momento no qual o homem pode acompanhar a mãe em sua rotina de preparação para o nascimento do filho. Cabe salientar que o envolvimento paterno durante a gestação não se restringe à adoção de comportamentos como acompanhar consultas e exames, todavia pode incluir o vínculo emocional com a mulher e o filho (Piccinini et al., 2009; Wenzel \& Mardini, 2013).

Uma das implicações dessas mudanças nos modos de tornar-se pai é a escolha, cada vez mais comum, por parte das gestantes, do pai como acompanhante durante o parto (Motta \& Crepaldi, 2005). Esse conjunto de transiçōes vai sedimentando no sujeito um processo que pode vir carregado de sentimentos que até mesmo remontam suas primeiras relações e, fundamentalmente, o modo como experiencia sua própria relação com seu genitor.

Em uma perspectiva psicodinâmica, a construção da paternidade, assim como também discutido na maternidade, pode se estruturar tendo como modelo as referências dos próprios pais, o que pode envolver movimentos de permanência, de ruptura, de reelaborações e de remalhagens de vínculos estabelecidos anteriormente (Benghozi, 2010; Scorsolini-Comin \& Santos, 2016). Assim, a 
chamada nova paternidade não se constituiria de modo linear. Ela recuperaria aspectos sociais e culturais que incidem sobre o homem e seu papel, além de elementos que atravessam suas experiências familiares na família de origem (Gomes \& Resende, 2004). Com base nesse panorama, o objetivo deste estudo é apresentar uma revisão integrativa da literatura científica, a fim de identificar qual a relevância do envolvimento paterno para mãe e bebê, desde a gestação, e outras variáveis relacionadas a essa dinâmica familiar.

\section{MÉTODO}

\subsection{Tipo de estudo}

Este estudo caracteriza-se como uma revisão integrativa, que tem como uma de suas metas a busca de evidências consolidadas na literatura para a Prática Baseada em Evidências (PBE) (Scorsolini-Comin, 2014). Trata-se de um método de pesquisa que propicia acesso à busca, à análise crítica e à síntese das evidências de pesquisas relevantes disponíveis na literatura do tema sondado, que culmina no estado atual e lapidado do conhecimento do conteúdo apurado, na identificação de lacunas que orientam estudos futuros e na potencialidade da transferência de conhecimento novo para a prática de intervençôes eficazes, fundamentando condutas ou tomadas de decisão (Mendes, Silveira, \& Galvão, 2008).

Seguindo protocolos internacionais para os estudos de revisão integrativa, a questão norteadora foi definida a partir do método PICO (P = participantes; I = intervenção; $\mathrm{C}=$ comparação; $\mathrm{O}=$ resultado/desfecho) (Santos, Pimenta, $\&$ Nobre, 2007), ficando redigida desse modo, com base em adaptaçôes pertinentes à área na qual este estudo se situa: ao longo do desenvolvimento infantil, qual a relevância $(\mathrm{O})$ do envolvimento paterno $(\mathrm{I})$ para mãe e bebê $(\mathrm{P})$ ?

Esta revisão utilizou como banco de evidências estudos publicados na Literatura Latino-Americana e do Caribe em Ciências da Saúde (Lilacs), na Scientific Electronic Library Online (Scielo) e nos Periódicos Eletrônicos de Psicologia (Pepsic). Os unitermos utilizados foram "gestação", "envolvimento paterno" e "paternidade", bem como seus correspondentes no idioma inglês.

\subsection{Critérios de inclusão e de exclusão}

Foram inclusos artigos científicos completos, indexados nas bases de dados supracitadas, em português, publicados entre 2004 e 2015, que tinham a temática relacionada com o objetivo do estudo e que contribuíssem para responder à 
questão norteadora. $\mathrm{O}$ recorte temporal buscou produções recentes, decisão respaldada em literatura que afirma que também são datados dos últimos anos estudos que conferem maior destaque à figura paterna (Colleti \& ScorsoliniComin, 2015). Produções com suporte de texto distinto de artigos publicados em periódicos foram excluídas (teses de doutorado, dissertações de mestrado, monografias de conclusão de curso, resenhas, cartas, editoriais, notícias, livros e capítulos) e também as que se encontravam fora do período temporal estabelecido, aquelas que não condiziam com o tema (por exemplo, a respeito de depressão pós-parto, parto prematuro, gestantes em condições especiais, entre outros eventos gestacionais que não destacavam a relevância do pai no processo) e que não propiciavam a resposta à questão norteadora.

\subsection{Procedimentos de coleta e análise de dados e de definição amostral}

Tão logo os procedimentos anteriormente descritos foram seguidos, as leituras dos títulos e dos resumos foram feitas para a seleção dos artigos. Os selecionados nessa etapa foram lidos na íntegra, e os que se enquadravam nos critérios de inclusão foram recuperados.

Após a leitura dos artigos, uma nova seleção foi realizada, restando apenas os estudos que compuseram o corpus. A sequência desse procedimento está representada na figura 1. Esse método foi realizado por dois juízes independentes, ambos com formação em Psicologia e com repertório no campo dos estudos sobre família.

A amostra analisada foi constituída de produções que tratavam do envolvimento paterno na relação mãe e bebê/criança desde a gestação até o puerpério. O corpus foi analisado em termos de seus objetivos, principais resultados e conclusões. A discussão, por sua vez, foi dividida em três subitens, surgidos a partir da análise:
a) a transição para a paternidade durante a gravidez;
b) a assunção do tornar-se pai; e
c) paternidade: entre o tradicional e o contemporâneo. 
Figura 1. Fluxograma com os procedimentos de seleção dos artigos

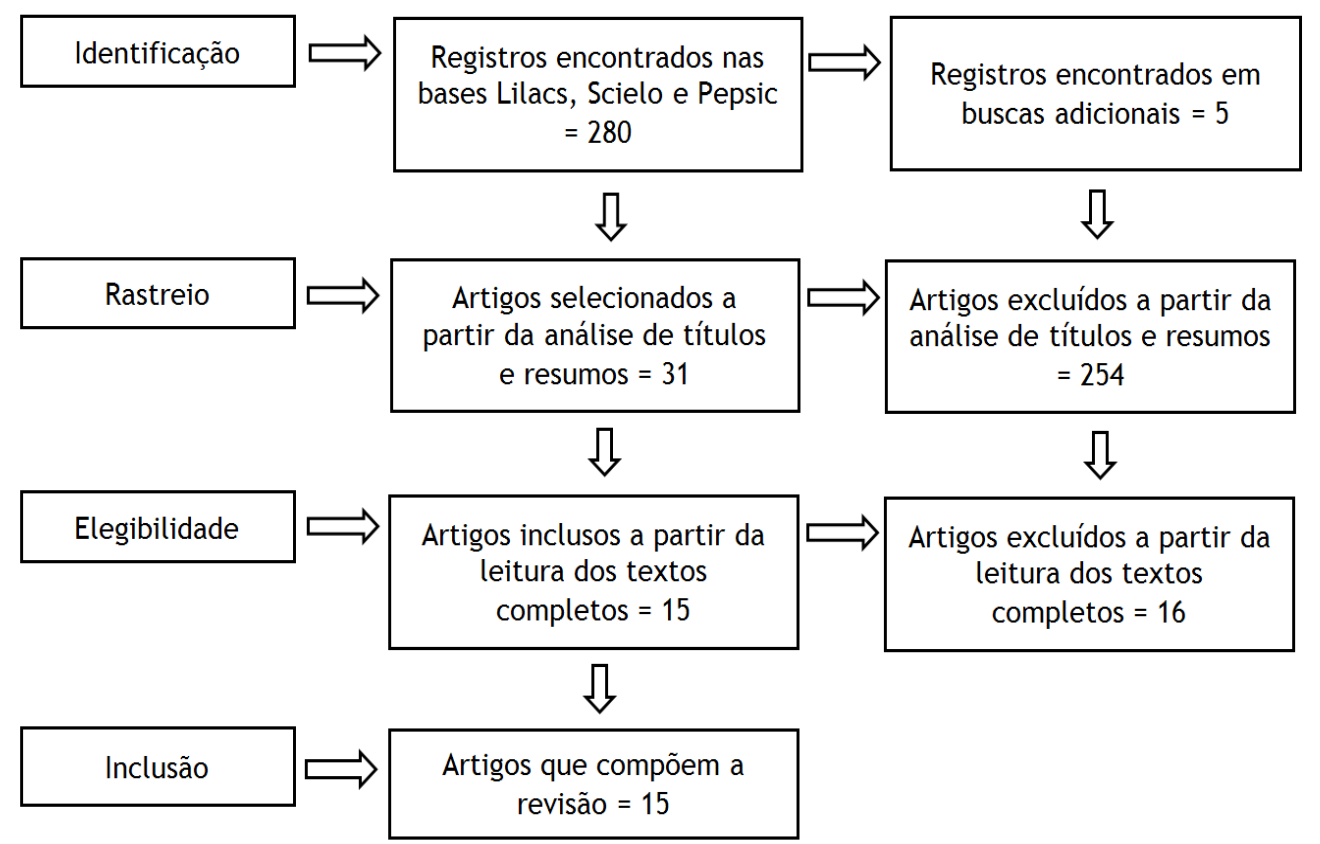

Fonte: Elaborado pelos autores.

\section{RESULTADOS}

\subsection{Caracterização geral do corpus}

Os artigos recuperados foram caracterizados em termos de título, autores, instituição de afiliação dos autores, periódico divulgador, ano de publicação, tipo de estudo, amostra e instrumentos (tabela 1). Os resultados indicaram que a maior parte da produção científica acerca do tema debatido se concentrou entre os anos de 2007 e 2015, e foi desenvolvida em instituições brasileiras, notadamente localizadas na Região Sul, sendo que outras duas eram de países estrangeiros em caráter complementar (Argentina e Estados Unidos) e uma da Colômbia.

A maior parte das publicações é de caráter empírico, sendo três estudos teóricos. A maioria dos estudos empíricos propõe tratamento de dados qualitativo. Sobre instrumentos utilizados em coleta de dados, foram encontrados questionários de caracterização sociodemográfica, entrevistas semiestruturadas e roteiros de entrevista específicos, como entrevista de contato inicial e a entrevista sobre a gestação e as expectativas do futuro pai (Piccinini et al., 2004; Piccinini et al., 2009). Dois estudos apresentaram amostra de corte longitudinal (Castoldi, Gonçalves, \& Lopes, 2014; Dessen \& Oliveira, 2012), em contraposição ao restante, que 
apresentou corte transversal para composição amostral. $\mathrm{O}$ único periódico que se repetiu foi Psicologia: Reflexão e Crítica, o que provavelmente reflete a existência, nele, de uma seção específica sobre Psicologia do desenvolvimento.

Tabela 1. Caracterização geral dos artigos recuperados $(\mathrm{N}=15)$

\begin{tabular}{|c|c|c|c|c|c|c|}
\hline $\mathbf{N}$ & Referência & $\begin{array}{c}\text { Afiliação } \\
\text { Institucional } \\
\text { do primeiro } \\
\text { autor }\end{array}$ & Periódico & Tipo de Estudo & Amostra & Instrumentos \\
\hline 1 & $\begin{array}{l}\text { Piccinini et al. } \\
\qquad(2004)\end{array}$ & $\begin{array}{l}\text { Universidade } \\
\text { Federal do } \\
\text { Rio Grande } \\
\text { do Sul }\end{array}$ & $\begin{array}{l}\text { Psicologia: } \\
\text { Reflexão e } \\
\text { Crítica }\end{array}$ & $\begin{array}{l}\text { Empírico, } \\
\text { misto, } \\
\text { transversal }\end{array}$ & $\begin{array}{c}35 \text { pais, } 21 \text { a } \\
40 \text { anos de } \\
\text { idade }\end{array}$ & $\begin{array}{c}\text { Entrevista de } \\
\text { contato inicial e } \\
\text { de expectativas } \\
\text { sobre a } \\
\text { paternidade }\end{array}$ \\
\hline 2 & $\begin{array}{c}\text { Almeida \& } \\
\text { Hardy (2007) }\end{array}$ & $\begin{array}{l}\text { Universidade } \\
\text { Federal de } \\
\text { Mato Grosso } \\
\text { do Sul }\end{array}$ & $\begin{array}{c}\text { Revista de } \\
\text { Saúde Pública }\end{array}$ & $\begin{array}{l}\text { Empírico, } \\
\text { qualitativo, } \\
\text { transversal }\end{array}$ & $\begin{array}{c}13 \text { pais } \\
\text { adolescentes }\end{array}$ & Entrevista \\
\hline 3 & $\begin{array}{c}\text { Bornholdt, } \\
\text { Wagner \& } \\
\text { Staudt (2007) }\end{array}$ & $\begin{array}{l}\text { Universidade } \\
\text { del Salvador }\end{array}$ & $\begin{array}{l}\text { Psicologia } \\
\text { Clínica }\end{array}$ & $\begin{array}{l}\text { Empírico, } \\
\text { qualitativo, } \\
\text { transversal }\end{array}$ & $\begin{array}{l}5 \text { pais, } 27 \text { a } \\
35 \text { anos de } \\
\text { idade }\end{array}$ & Entrevista \\
\hline 4 & $\begin{array}{l}\text { Freitas, Coelho } \\
\text { \& Silva (2007) }\end{array}$ & $\begin{array}{l}\text { Universidade } \\
\text { Federal da } \\
\text { Paraíba }\end{array}$ & $\begin{array}{l}\text { Cadernos de } \\
\text { Saúde Pública }\end{array}$ & $\begin{array}{l}\text { Empírico, } \\
\text { qualitativo, } \\
\text { transversal }\end{array}$ & $\begin{array}{l}10 \text { pais, } 20 \text { a } \\
33 \text { anos de } \\
\text { idade }\end{array}$ & Entrevista \\
\hline 5 & $\begin{array}{c}\text { Oliveira, } \\
\text { Ferreira, Silva, } \\
\text { Ferreira, } \\
\text { Seabra \& } \\
\text { Fernando } \\
\text { (2009) }\end{array}$ & $\begin{array}{l}\text { Universidade } \\
\text { Federal de } \\
\text { Pernambuco }\end{array}$ & $\begin{array}{c}\text { Cogitare } \\
\text { Enfermagem }\end{array}$ & $\begin{array}{l}\text { Empírico, } \\
\text { quantitativo, } \\
\text { transversal }\end{array}$ & $\begin{array}{l}13 \text { homens/ } \\
\text { pais, } 22 \text { a } 31 \\
\text { anos de idade }\end{array}$ & Questionário \\
\hline 6 & $\begin{array}{l}\text { Piccinini et al. } \\
\qquad(2009)\end{array}$ & $\begin{array}{l}\text { Universidade } \\
\text { Federal do } \\
\text { Rio Grande } \\
\text { do Sul }\end{array}$ & $\begin{array}{l}\text { Psicologia: } \\
\text { Reflexão e } \\
\text { Crítica }\end{array}$ & $\begin{array}{l}\text { Empírico, } \\
\text { misto, } \\
\text { transversal }\end{array}$ & $\begin{array}{c}35 \text { pais, } 21 \text { a } \\
40 \text { anos de } \\
\text { idade }\end{array}$ & $\begin{array}{c}\text { Entrevista de } \\
\text { contato inicial e } \\
\text { de expectativas } \\
\text { sobre a } \\
\text { paternidade }\end{array}$ \\
\hline 7 & Benczik (2011) & $\begin{array}{l}\text { Universidade } \\
\text { Federal do } \\
\text { Rio Grande } \\
\text { do Sul }\end{array}$ & $\begin{array}{c}\text { Revista } \\
\text { Psicopedagogia }\end{array}$ & Teórico & Não se aplica & Não se aplica \\
\hline 8 & $\begin{array}{c}\text { Dessen \& } \\
\text { Oliveira (2012) }\end{array}$ & $\begin{array}{l}\text { Universidade } \\
\text { de Brasília }\end{array}$ & $\begin{array}{l}\text { Psicologia: } \\
\text { Reflexão e } \\
\text { Crítica }\end{array}$ & $\begin{array}{l}\text { Empírico, } \\
\text { misto, } \\
\text { transversal }\end{array}$ & $\begin{array}{l}45 \text { mulheres } \\
\text { grávidas e } 42 \\
\text { mães com } \\
\text { bebês de até } \\
6 \text { meses }\end{array}$ & $\begin{array}{c}\text { Questionário e } \\
\text { entrevista }\end{array}$ \\
\hline 9 & $\begin{array}{c}\text { Zampieri, } \\
\text { Guesser, } \\
\text { Buendgens, } \\
\text { Junckes \& } \\
\text { Rodrigues } \\
\text { (2012) }\end{array}$ & $\begin{array}{l}\text { Universidade } \\
\text { Federal } \\
\text { de Santa } \\
\text { Catarina }\end{array}$ & $\begin{array}{l}\text { Revista } \\
\text { Eletrônica de } \\
\text { Enfermagem }\end{array}$ & $\begin{array}{l}\text { Empírico, } \\
\text { qualitativo, } \\
\text { modalidade } \\
\text { convergente- } \\
\text { assistencial }\end{array}$ & 5 casais & $\begin{array}{c}\text { Entrevistas, } \\
\text { visitas e prática } \\
\text { educativa }\end{array}$ \\
\hline
\end{tabular}




\begin{tabular}{|c|c|c|c|c|c|c|}
\hline 10 & $\begin{array}{c}\text { Henn \& } \\
\text { Piccinini } \\
(2013)\end{array}$ & $\begin{array}{l}\text { Universidade } \\
\text { Federal do } \\
\text { Rio Grande } \\
\text { do Sul }\end{array}$ & $\begin{array}{c}\text { Estudos de } \\
\text { Psicologia } \\
\text { (Natal) }\end{array}$ & $\begin{array}{l}\text { Empírico, } \\
\text { qualitativo, } \\
\text { longitudinal }\end{array}$ & $\begin{array}{c}3 \text { casais } \\
\text { adolescentes }\end{array}$ & $\begin{array}{l}\text { Entrevistas } \\
\text { sobre } \\
\text { relacionamento } \\
\text { conjugal e } \\
\text { paternidade, } \\
\text { ficha sobre } \\
\text { práticas sexuais }\end{array}$ \\
\hline 11 & $\begin{array}{l}\text { Simas, Souza } \\
\text { \& Scorsolini- } \\
\text { Comin (2013) }\end{array}$ & $\begin{array}{c}\text { Centro } \\
\text { Universitário } \\
\text { Unifafibe }\end{array}$ & $\begin{array}{c}\text { Psicologia: } \\
\text { Teoria e Prática }\end{array}$ & $\begin{array}{l}\text { Empírico, } \\
\text { qualitativo, } \\
\text { transversal }\end{array}$ & 6 gestantes & Entrevista \\
\hline 12 & $\begin{array}{c}\text { Castoldi, } \\
\text { Gonçalves \& } \\
\text { Lopes (2014) }\end{array}$ & $\begin{array}{l}\text { Universidade } \\
\text { Vale do Rio } \\
\text { dos Sinos }\end{array}$ & $\begin{array}{l}\text { Psicologia em } \\
\text { Estudo }\end{array}$ & $\begin{array}{c}\text { Empírico, } \\
\text { qualitativo, } \\
\text { longitudinal }\end{array}$ & $\begin{array}{c}6 \text { casais } \\
\text { primíparos }\end{array}$ & Entrevista \\
\hline 13 & $\begin{array}{c}\text { Gomes, } \\
\text { Bossardi, Cruz, } \\
\text { Crepaldi \& } \\
\text { Vieira (2014) }\end{array}$ & $\begin{array}{c}\text { Universidade } \\
\text { Federal } \\
\text { de Santa } \\
\text { Catarina }\end{array}$ & $\begin{array}{l}\text { Avaliação } \\
\text { Psicológica }\end{array}$ & Teórico & Não se aplica & Não se aplica \\
\hline 14 & $\begin{array}{c}\text { Colleti \& } \\
\text { Scorsolini- } \\
\text { Comin }(2015)\end{array}$ & $\begin{array}{l}\text { Universidade } \\
\text { Federal do } \\
\text { Triângulo } \\
\text { Mineiro }\end{array}$ & Psico & $\begin{array}{l}\text { Empírico, } \\
\text { qualitativo, } \\
\text { transversal }\end{array}$ & $\begin{array}{c}4 \text { pais com } \\
\text { mais de } 40 \\
\text { anos de idade }\end{array}$ & Entrevista \\
\hline 15 & $\begin{array}{l}\text { Bittencourt, } \\
\text { Paraventi, } \\
\text { Bueno, } \\
\text { Sabbag, Schulz } \\
\text { \& Vieira (2015) }\end{array}$ & $\begin{array}{c}\text { Universidade } \\
\text { Federal } \\
\text { de Santa } \\
\text { Catarina }\end{array}$ & $\begin{array}{c}\text { Estudos e } \\
\text { Pesquisas em } \\
\text { Psicologia }\end{array}$ & Teórico & Não se aplica & Não se aplica \\
\hline
\end{tabular}

Fonte: elaborado pelos autores.

\subsection{Objetivos dos estudos recuperados}

Os artigos objetivaram, em sua maioria, averiguar o discurso de gestantes (Dessen \& Oliveira, 2012; Simas, Souza, \& Scorsolini-Comin, 2013), de casais (Zampieri, Guesser, Buendgens, Junckes, \& Rodrigues, 2012) e de pais acerca da vivência da gravidez (Bornholdt, Wagner, \& Staudt, 2007; Piccinini et al., 2004; Piccinini et al., 2009) de suas expectativas e experiências (Freitas, Coelho, \& Silva, 2007) e do exercício de algumas funções e das relações de gênero que permeiam a parentalidade (Almeida \& Hardy, 2007; Benczik, 2011).

Algumas investigações se propuseram a elencar os fatores relacionados ao envolvimento paterno (Bittencourt et al., 2015; Castoldi et al., 2014; Oliveira et al., 2009) na adolescência (Henn \& Piccinini, 2013) e na meia idade (Colleti \& Scorsolini-Comin, 2015). Um estudo dedicou-se à avaliação dos instrumentos para a mensuração do envolvimento paterno (Gomes, Bossardi, Cruz, Crepaldi, \& Vieira, 2014).

\subsection{Principais resultados dos estudos}

Os resultados obtidos e relatados nos artigos demonstraram, no geral, a 
importância do pai como matriz de apoio para sua companheira nos períodos gestacional e puerperal; a constante presença da função paterna tradicional, sua progressiva modificação e as repercussões que essas mudanças acarretaram; os modelos familiares de parentalidade como aspectos influentes no posterior envolvimento dos pais, na atualidade, e a satisfação de mães com o envolvimento paterno oferecido, apesar de ainda avaliarem-no como aquém de suas expectativas.

Observou-se a condição de vulnerabilidade dos pais na paternidade em virtude da socialização de gênero nos moldes tradicionais, especialmente em adolescentes (demonstrados por meio da incorporação precoce de alguns papéis) (Almeida \& Hardy, 2007). No entanto esses moldes apresentam uma lenta, mas progressiva modificação.

Em situaçôes institucionais, verificou-se também o papel fundamental dos profissionais de saúde de atuarem no processo educacional e na motivação do engajamento paterno em consonância com o apoio materno (Oliveira et al., 2009). Evidenciou-se o crescente desejo do pai por uma maior proximidade e participação desde a gestação e no desenvolvimento dos filhos, sendo tal envolvimento substancial para sedimentar o seu papel, para fornecer suporte para a gestante e como uma boa base para o desenvolvimento integral do filho (Benczik, 2011; Dessen \& Oliveira, 2012; Simas et al., 2013; Zampieri et al., 2012). A assunção desse novo papel, no entanto, pode ser permeada por limitações e potencialidades (Henn \& Piccinini, 2013; Piccinini et al., 2009; Piccinini et al., 2004), aviltando a necessidade de uma escuta que, de fato, considere a paternidade num cenário de transformação (Bittencourt et al., 2015; Bornholdt et al., 2007; Castoldi et al., 2014), aliada a elementos da conjugalidade e da história geracional (Colleti \& Scorsolini-Comin, 2015; Freitas et al., 2007), o que envolve a necessidade de incrementos nas pesquisas na área, quer seja por meio de instrumentos quantitativos ou qualitativos (Gomes et al., 2014).

\section{DISCUSSÃO}

Observa-se que o cenário atual de paternidade compõe-se pela coexistência de um modelo paternal emergente, caracterizado por novas formas de exercer esse papel, e o modelo paterno tradicional, seguindo a lógica de uma construção patriarcalista (Almeida \& Hardy, 2007; Benczik, 2011; Bornholdt et al., 2007; Castoldi et al., 2014; Dessen \& Oliveira, 2012; Freitas et al., 2007; Henn \& Piccinini, 2013; Oliveira et al., 2009; Piccinini et al., 2004; Simas et al., 2013; Zampieri et al., 2012). Com base nisso, tem sido possível reconhecer movimentos de reorganização das famílias e de papéis, processos de reestruturação e readaptação, redimensionamento de valores, de expectativas e de prioridades 
(Bornholdt et al., 2007). Esses aspectos serão discutidos mais detidamente a seguir.

\subsection{A transição para a paternidade durante a gravidez}

Para Freitas et al. (2007), a paternidade toma como referência os modelos vigentes de masculinidades e feminilidades que se baseiam nas diferenças biológicas entre os sexos e nas representações ideológicas construídas em torno do ser homem ou mulher. Diante dessa construção social masculina e feminina, Dessen e Oliveira (2012) postulam o ser pai como diferente e até certo ponto oposto ao ser mãe, haja vista que, à proporção que as mulheres se envolvem com os filhos e a casa, os homens tendem a se distanciar. Entretanto, independentemente das mudanças nos papéis de gênero, a presença do pai (ou de seu substituto) contribui de modo expressivo para o desenvolvimento afetivo, social, e emocional da criança.

Desde a gestação, o envolvimento paterno pode ser observado a partir de diferentes comportamentos, como preocupações em relação ao bebê e à mãe, bem como sua participação direta na gestação e a interação pai-bebê (Piccinini et al., 2009; Piccinini et al., 2004). Para Freitas et al. (2007), o estabelecimento de uma maior vinculação entre pai e filho durante a gravidez potencializa o desenvolvimento da paternidade e desse vínculo após o nascimento, repercutindo positivamente em um maior envolvimento e na maior proximidade dessa díade. A participação paterna na fase da gravidez possibilita que o homem se integre melhor ao processo, o que também pode repercutir positivamente em uma melhor vinculação com a mulher, com menos conflitos e maior satisfação em termos do relacionamento amoroso estabelecido (Freitas et al., 2007).

O estudo de Colleti e Scorsolini-Comin (2015) complementa essa perspectiva mediante relato de alguns homens que foram pais, pela primeira vez, após os 40 anos. A participação deles demonstrou melhores aspectos na relação conjugal e sensação de completude do casal após o nascimento dos filhos, o que exige compreensão e adaptação de ambas as partes. Nessa participação gravídica paterna, salientaram-se, ainda, as verbalizações que referiam apoio emocional e material à gestante, acompanhamento às consultas pré-natais e ecografias, e envolvimento com os preparativos para a chegada do bebê.

No estudo de Piccinini et al. (2004), os participantes, pais que esperavam seu primeiro filho, relataram apoiar emocionalmente sua companheira, estando mais disponíveis, pacientes e compreensivos. Mais de um terço deles referiu ter conhecimentossobreodesenvolvimentodeseubebê,obtidosnoacompanhamento, o que é indicativo do interesse que tinham pelo desenvolvimento de seus filhos 
e refletia suas preocupações a respeito da saúde do bebê. Apesar disso, é também indicativo de que, embora os pais estejam bastante envolvidos em alguns aspectos da gestação, ela ainda é um campo de interesse majoritário das mulheres. Os pais desse estudo relataram buscar situações de interação com os filhos, visando a uma maior proximidade por meio de conversas, lendo histórias e acariciando a barriga da gestante. Para esses autores, "esta disponibilidade para a relação com o bebê reflete proximidade bastante real da paternidade, além de envolvimento emocional com o bebê, demonstrando o movimento de um novo pai" (Piccinini et al., 2004, p. 311).

Os resultados obtidos por Piccinini et al. (2004) revelaram, além disso, que os pais manifestaram diversas preocupaçōes durante a gravidez de suas companheiras, mostrando-se como importante fonte de apoio emocional a elas, corroborando o relato de Simas et al. (2013). Contudo é importante destacar que quase um terço dos pais do estudo de Piccinini et al. (2004) afirmou não se preocupar com a gestação especificamente, mesmo tendo frisado preocupações em outros momentos. Também foram referidas poucas interaçôes com o bebê, o que pode ser explicado por dificuldades relatadas e, ou, de sentimentos de inadequação paterna. A hipótese desses últimos autores, também aventada por Freitas et al. 2007, foi a de que esses pais ainda não sentiam o bebê como algo real, concreto, dificultando a comunicação e a interação nessa fase.

\subsection{A assunção do "tornar-se pai"}

O sentir-se pai pode emergir em diferentes momentos, com a notícia da gravidez e com as experiências do pré-natal e mais ao final da gestação, ou mesmo com o nascimento da criança e com as vivências posteriores em família (Freitas et al., 2007)). Avaliar esse envolvimento paterno ao longo do tempo, no período gravídico ou no pós-parto, mostra-se importante para compreender se os desafios e as características dessa experiência paterna se alteram com as diferentes necessidades emergentes (Gomes et al., 2014).

Freitas et al. 2007 propuseram que a dificuldade de o "pai sentir a gravidez como experiência compartilhada com mulher-filho(a) também pode ser relacionada com a reprodução ideológica da noção de homem/pai e mulher/ mãe, historicamente construída e culturalmente preservada” (p. 141). Essa noção frequentemente opera a exclusão de uma participação mais concreta nesse processo, o que tende a reforçar relações de gênero na paternidade. Por outro lado, Bornholdt et al. (2007) explicitaram que esse momento está cada vez menos restrito ao universo feminino, haja vista a participação do pai em diferentes momentos desse processo e de diferentes formas: na oferta de cuidado, 
nas preocupações verbalizadas ou mesmo em seu processo de preparação para a chegada do filho, em termos materiais e emocionais.

Em relação às preocupações financeiras que envolvem o preparo material para a chegada de um novo membro da família, ainda que presentes no relato de vários pais, não foram as predominantes para os entrevistados no estudo de Piccinini et al. (2009). Porém, o significado que o trabalho e sua inserção tem na vida das pessoas depende igualmente da condição socioeconômica daqueles (Almeida \& Hardy, 2007). Para muitos pais, a primeira responsabilidade social é com o provimento financeiro familiar, o que denota que a paternidade não gira em torno de apenas ter filhos, mas de conseguir provê-los materialmente (Freitas et al., 2007).

Complementarmente a isso, no estudo de Dessen e Oliveira (2012), estar trabalhando significa um bom desempenho da paternidade. Os dados do estudo de Zampieri et al., 2012) confirmaram que o trabalho é um fator que dificulta a participação dos pais nas consultas pré-natais e em outros momentos cruciais da gestação e do puerpério. Esses autores enfatizaram a sobrecarga de trabalho e o cansaço dele decorrente, os horários de trabalho coincidentes com consultas e grupos educativos e, especialmente, a visão e o comportamento dos empregadores que costumam não valorizar a importância da participação do homem na atenção pré-natal. Ainda, como analisaram Oliveira et al. (2009), tais aspectos reforçam que envolver nesse tipo de atividade acaba por ser compreendidos como algo atinente ao papel feminino, excluindo o pai desse processo e promovendo a ideia de que apenas a mulher deve ser cuidada e atendida em suas necessidades, ou nem sequer aviltando a possibilidade de que o homem possa exercer esse papel de cuidado para com a gestante e a futura mãe. Também a mãe, nessa mesma perspectiva de gênero, acaba por ter sua figura desassociada de seu papel no mundo do trabalho.

De acordo com as análises de Oliveira et al. (2009), outros motivos que influenciaram a não participação do homem/pai no pré-natal e em atividades de acompanhamento no processo gestacional foram a falta de interesse e a ausência do conhecimento do direito da participação do pai em consultas, a falta de incentivo/convite por parte dos profissionais envolvidos. Durante o pré-natal, percebe-se que o profissional de saúde tende a concentrar as consultas no bebê e na gestante, excluindo e, ou, tornando o homem/pai um mero expectador. Por outro lado, no estudo de Piccinini et al. (2004), observou-se que muitos cursos de gestantes oferecidos por serviços de saúde excluíam o pai desse processo, convidando apenas as mães ou mesmo não permitindo a presença do pai.

Participar de consultas, assim como de outros eventos envolvendo o período 
gestacional, possibilita ao homem apreender e inteirar-se melhor nesse processo (Oliveira et al., 2009; Piccinini et al., 2004). Oliveira et al. (2009) reforçaram argumentos de que o pai também deve ser assistido por profissionais alocados em equipamentos de saúde. Eles têm o direito de participar do pré-natal e de receber informações necessárias ao longo da gravidez, como mudanças físicas e emocionais vivenciadas pela mulher, e podem, também, dirimir dúvidas ao longo desse acompanhamento. Logo, o homem/pai ocupará um lugar que é legitimamente seu e poderá prover à companheira o apoio que ela necessita. Ainda, para Benczik (2011), há muitos pais que não têm ocupado esse lugar, seja por não almejarem ocupá-lo ou por crerem que não podem fazê-lo.

Conforme o pai recebe orientações e compreende seus direitos de acompanhar a gestante/companheira nas consultas pré-natal, no parto e no pós-parto, isso pode favorecer um maior vínculo dessa paternidade, proporcionando ao homem/pai a compreensão das mudanças que acontecem nesse período e que estão associadas a seu papel na sociedade e na família (Dessen \& Oliveira, 2012; Freitas et al., 2007; Oliveira et al., 2009). Além disso, também favorece a percepção do impacto e da importância que a função paterna tem no desenvolvimento cognitivo, social e emocional dos filhos (Benczik, 2011).

Visto a mídia participar da construção das subjetividades e a necessidade progressiva que o pai tem de se atualizar e de conquistar novas demandas sociais, existe uma crescente busca de informações realizada por pais em relação à paternidade em sites, blogs, revistas e livros. Ao popularizar conhecimentos produzidos pela ciência, a mídia atua na produção, veiculação e acessibilidade ao envolvimento paterno e discursos sobre a paternidade. O estudo de Bittencourt et al. (2015), por meio de análises de revistas com essa temática, demonstrou a realidade que tem ocorrido em algumas famílias, mas que não necessariamente é vivenciada por todos os pais (as discutidas mudanças de papéis e participação mais atuante do pai no cenário familiar e doméstico), publicações estas que refletem as transformaçōes sociais e a emergência do "novo pai". As revistas investigadas neste estudo, em termos gerais, ressaltaram aspectos positivos da paternidade, com referências a pais envolvidos, disponíveis, responsáveis e interativos com seus filhos, com fins de reforçar o valor da figura paterna no vínculo familiar e filial.

\subsection{Paternidade: entre o tradicional e o contemporâneo}

Em síntese, os participantes da maioria dos estudos apresentaram, em seus depoimentos, vivências de paternidade que ora apontaram a perspectiva do modelo de um "novo pai", ora se ancoraram no modelo tradicional de pai. 
Assim, embora o desejo de muitos pais a partir das retóricas contemporâneas seja o de se aproximar desse ideal, frequentemente a prática da paternidade ainda tende a reiterar papéis de gênero normativos e resgatar experiências parentais associadas a esse caráter mais tradicional. Nesse bojo, uma importante ressalva é apresentada por Castoldi et al. (2014). Eles destacam haver especificidades contextuais, microssociais e no seio de cada família que particularizam casos e experiências, devendo-se atentar para o risco de leituras generalizantes que balizem como deve ser o envolvimento com os filhos.

A produção de Colleti e Scorsolini-Comin (2015) exprime uma das facetas dessa singularidade, ao abranger a primeira experiência da paternidade na meiaidade e os aspectos subjetivos que a perpassam, especialmente a percepção da relação vivida no passado com o próprio genitor. Essas percepções contribuem para a construção do exercício da paternidade e para o relacionamento com os filhos, sendo que esse modelo de genitor pode ser transmitido transgeracionalmente, como corroborado pelo estudo de Bittencourt et al. (2015). Pensar a assunção da paternidade em diferentes momentos do ciclo vital e em diversos contextos sociais, econômicos e culturais tem encontrado reflexo na literatura científica, favorecendo, assim, a apropriação das atuais transformações de modelos e formas de ser pai e de ser família (Walsh, 2016).

Dessa maneira, os dois significados convivem, por vezes, de forma conflituosa e antagônica, e se transformam gradativamente com as novas mudanças sociais e de papéis do homem e da mulher, ampliado e ressignificando o papel de pai. Conforme este se envolve com a gravidez, com sua companheira e com seu filho, e procura se inserir no processo, constrói e sedimenta dinamicamente o papel de pai (Freitas et al., 2007). Nesse processo, Bornholdt et al. (2007) compreendem que o mais importante é refletir que tal movimento opera diversas possibilidades no exercício da paternidade, pondo em xeque valores e definições de outrora e potencializando novas descrições e experiências.

A esse respeito, Freitas et al. (2007) postulam que o sentir-se pai pode ser concebido e vivido como um direito e um dever. $\mathrm{O}$ direito refere-se à possibilidade de vivenciar essa experiência sem o estigma da afirmação sexual, ao passo que o dever recupera a sua responsabilidade para com o filho, sendo partícipe dos cuidados e na divisão de tarefas. Identificar essas mudanças estruturais no interior dos núcleos familiares permite contextualizar novas demandas socioculturais e transformar os modelos existentes, tradicionais, que tendem a limitar o desenvolvimento e as experiências subjetivas do pai como "amoroso, responsável e unificador" (Benítez \& Cárdenas, 2010, p. 89). Como frisado de modo uníssono na literatura ora consultada, essas mudanças estão em curso e devem ser permanentemente investigadas em suas características e nuanças, a 
fim de ampliar a compreensão sobre a paternidade e, de modo especial, sobre o envolvimento paterno.

\section{CONSIDERAÇÕES FINAIS}

A revisão de literatura proposta permitiu integrar diversidade de objetivos, de resultados e de conclusões de estudos propostos em realidades e tempos distintos, por autores vinculados a instituições diversas, incluindo-se aquelas estrangeiras. Esse exercício permitiu verificar retratos que podem ser auxiliares na (re)construção e redefinição do lugar do pai na família e na sociedade. $O$ cenário desenhado permite visualizar algo que se tem convertido em grandes desafios vividos para homens e mulheres na Contemporaneidade, haja vista a rígida divisão de papéis sexuais e de gênero que ainda se mostra consolidada socialmente.

A despeito disso, esses papéis vêm sofrendo significativa e gradual transformação. Eles têm sido revestidos por maior equidade nas funções de gênero, fazendo emergir novos conceitos sobre pai/paternidade (e suas variações) e sobre homem. Esses novos sujeitos, apesar de não se desatrelarem completamente de velhas concepções, o que seria uma possibilidade teórica e empiricamente insustentável de ser mantida, dada a lentidão dos processos históricos, têm se distanciado de modelos rígidos e tradicionais, têm buscado participar do período gestacional de modo mais genuíno, criando vínculos com o bebê desde o útero, compartilhando vivências e emoções maternas, e também as tarefas diárias e domésticas destinadas até há pouco exclusivamente à mulher. Os diversos estudos aqui explorados parecem convergir para a necessidade da construção de novas formas de paternidade, ancoradas em crenças que fortaleçam o convívio afetivo como princípio para uma sociedade melhor (Benítez \& Cárdenas, 2010).

Em termos das limitações deste estudo, destacam-se as bases de dados utilizadas para efetuar as buscas de informação, o que gerou um filtro rigoroso e, por sua vez, promoveu redução significativa de amostra. Certamente a ampliação dos recursos de busca permitiria o alcance de outras produções e, por conseguinte, de novas problematizaçôes ou de reforço das ora apresentadas. Não obstante a opção metodológica seguida, pôde-se compreender de que modo a paternidade vem sendo compreendida nos estudos selecionados, o que, em última instância, espelha práticas de saúde e de cuidado para com esposas, mães e filhos, e reforça a assunção de compromissos mais sólidos com as funções parentais, por parte da comunidade acadêmica que produziu os estudos analisados.

Discutir esse panorama de modo sistematizado, como ora objetivado, permitiu averiguar mudanças ainda em operação e contribuiçôes relevantes no campo das 
relações familiares e especificamente no tocante ao envolvimento do pai (ou de seu substituto) quando da constituição da nova família. Aponta-se que o planejamento de estudos empíricos acerca da paternidade pode receber benefícios se o traçado apresentado for considerado, também fomentando a realização de estudos longitudinais que possam considerar de modo mais apropriado esses movimentos ao longo do tempo. 


\section{REFERÊNCIAS}

Almeida, A. F. F. \& Hardy, E. (2007). Vulnerabilidade de gênero para a paternidade em homens adolescentes. Revista Saúde Pública, 41(4), 565-572.

Benczik, E. B. P. (2011). A importância da figura paterna para o desenvolvimento infantil. Revista Psicopedagogia, 28(85), 67-75.

Benghozi, P. (2010). Malhagem, flitação e afliação: psicanálise dos vínculos: casal, familia, grupo, instituição e campo social. E. D. Galery (Trad.). São Paulo: Vetor.

Benítez, N. M. C. \& Cárdenas, C. H. R. (2010). La gestación: periodo fundamental para el nacimiento y el desarrollo del vínculo paterno. Avances en Enfermería, 28(2), 88-97.

Bittencourt, I. G., Paraventi, L., Bueno, R. K., Sabbag, G. M., Schulz, M. J. L. C., \& Vieira, M. L. (2015). Envolvimento paterno na mídia: publicações em revistas para pais e mães. Estudos e Pesquisas em Psicologia, 15(2), 688-707.

Bornholdt, E. A., Wagner, A., \& Staudt, A. C. P. (2007). A vivência da gravidez do primeiro filho à luz da perspectiva paterna. Psicologia Clínica, 19(1), 75-92.

Bossardi, C. N. \& Vieira, M. L. (2010). Cuidado paterno e desenvolvimento infantil. Revista de Ciências Humanas, 44(1), 205-221.

Campos, D. C. (2012). Saudade da família no futuro ou o futuro sem família? In M. N. Baptista \& M. L. M. Teodoro (Orgs.), Psicologia de familia: teoria, avaliação e intervenção. (pp. 74-86). Porto Alegre: Artmed.

Capitão, C. G. \& Romaro, R. A. (2012). Concepção psicanalítica da família. In M. N. Baptista \& M. L. M. Teodoro (Orgs.), Psicologia de família: teoria, avaliação e intervenção. (pp. 27-37). Porto Alegre: Artmed.

Castoldi, L., Gonçalves T. R., \& Lopes R. C. S. (2014). Envolvimento paterno da gestação ao primeiro ano de vida do bebê. Psicologia em Estudo, 2(19), 247259.

Colleti, M. \& Scorsolini-Comin, F. (2015). Pais de primeira viagem: a experiência da paternidade na meia-idade. Psico, 46(3), 374-385.

Dessen, M. A. \& Oliveira, M. R. (2012). Envolvimento paterno durante o nascimento dos filhos: Pai "real" e "ideal" na perspectiva materna. Psicologia: Reflexão e Crítica, 26(1), 184-192. 
Falceto, O. G. \& Waldemar, J. O. C. (2013). O ciclo vital da família. In C. L. Eizirik \& A. M. S. Bassols (Orgs.), O ciclo da vida humana: uma perspectiva psicodinâmica. (2a ed., pp. 95-110). Porto Alegre: Artmed.

Freitas, W. M. F., Coelho, E. A. C., \& Silva, A. T. M. C. (2007). Sentir-se pai: a vivência masculina sob o olhar de gênero. Cadernos de Saúde Pública, 23(1), $137-145$.

Garfield, C. F. (2015). Supporting fatherhood before and after it happens. Pediatrics, 135(2), 528-530.

Gomes, A. J. S. \& Resende, V. R. (2004). O pai presente: o desvelar da paternidade em uma família contemporânea. Psicologia: Teoria e Pesquisa, 20(2), 119-125.

Gomes, L. B., Bossardi, C. N., Cruz, R. M., Crepaldi, M. A., \& Vieira, M. L. (2014). Propriedades psicométricas de instrumentos de avaliação do envolvimento paterno: revisão de literatura. Avaliação Psicológica, 13(1), 1927.

Gorin, M. C., Mello, R., Machado, R. N., \& Féres-Carneiro, T. (2015). O estatuto contemporâneo da parentalidade. Revista da Spagesp, 16(2), 3-15.

Henn, C. G. \& Piccinini, C. A. (2013). Adolescência e função paterna: Da gestação ao primeiro ano de vida do bebê. Estudos de Psicologia, 18(4), 579588.

Lamb, M. E., Pleck, J. H., Charnov, E. L., \& Levine, J. A. (1985). Paternal behavior in humans. American Zoologist, 25(3), 883-894.

McGill, B. S. (2014). Navigating new norms of involved fatherhood. Journal of Family Issues, 35(8), 1089-1106.

Mendes, K. D. S., Silveira, R. C. C. P., \& Galvão, C. M. (2008). Revisão integrativa: método de pesquisa para a incorporação de evidências na saúde e na enfermagem. Texto \& Contexto Enfermagem, 17(4), 758-764.

Motta, C. C. L. \& Crepaldi, M. A. (2005). O pai no parto e apoio emocional: a perspectiva da parturiente. Paidéia, 15(30), 105-118.

Neves, M. A. (2013). Anotações sobre trabalho e gênero. Cadernos de Pesquisa, 43(149), 404-421. Recuperado a partir de https://dx.doi.org/10.1590/S010015742013000200003 
Oliveira, S. C., Ferreira, J. G., Silva, P. M. P., Ferreira, J. M., Seabra, A., \& Fernando, V. C. N. (2009). A participação do homem/pai no acompanhamento da assistência pré-natal. Cogitare Enfermagem, 14(1), 73-78.

Osório, L. C. (2013). Como trabalhar com sistemas humanos: grupos, casais e familias, empresas. Porto Alegre: Artmed.

Piccinini, C. A., Levandowski, D. A., Gomes, A. G., Lindenmeyer, D., \& Lopes, R. S. (2009). Expectativas e sentimentos de pais em relação ao bebê durante a gestação. Estudos de Psicologia, 26(3), 373-382.

Piccinini, C. A., Silva, M. R., Gonçalves, T. R., \& Lopes, R. S. (2004). O envolvimento paterno durante a gestação. Psicologia: Reflexão e Crítica, 17(3), 303-314.

Santos, C. M. C., Pimenta, C. A. M., \& Nobre, M. R. C. (2007). A estratégia PICO para a construção da pergunta de pesquisa e busca de evidências. Revista Latino-Americana de Enfermagem, 15(3), 508-511.

Scorsolini-Comin, F. (2014). Guia de orientação para iniciação científica. São Paulo: Atlas.

Scorsolini-Comin, F. \& Santos, M. A. (2016). Construir, organizar, transformar: considerações teóricas sobre a transmissão psíquica entre gerações. Psicologia Clínica, 28(1), 141-159.

Simas, F. B., Souza, L. V., \& Scorsolini-Comin, F. (2013). Significados da gravidez e da maternidade: discursos de primíparas e multíparas. Revista Psicologia: Teoria e Prática, 15(1), 19-34.

Staudt, A. N. C. \& Wagner, A. (2008). Paternidade em tempos de mudança. Psicologia: Teoria e Prática, 10(1), 174-185.

Vieira, M. L., Bossardi, C. N., Gomes, L. B., Bolze, S. D. A., Crepaldi, M. A., \& Piccinini, C. A. (2014). Paternidade no Brasil: revisão sistemática de artigos empíricos. Arquivos Brasileiros de Psicologia, 66(2), 36-52.

Walsh, F. (2016). Diversidade e complexidade nas famílias do século XXI. In F. Walsh (Org.), Processos normativos da familia: diversidade e complexidade. (4a ed., pp. 3-27). Porto Alegre: Artmed.

Wenzel, M. P. \& Mardini, V. (2013). Gestação, parto e puerpério. In C. L. Eizirik \& A. M. S. Bassols (Orgs.), O ciclo da vida humana: uma perspectiva 
psicodinâmica. (2a ed., pp. 63-76). Porto Alegre: Artmed.

Zampieri, M. F. M., Guesser, J. C., Buendgens, B. B., Junckes, J. M., \& Rodrigues, I. G. (2012). O significado de ser pai na ótica de casais grávidos: limitações e facilidades. Revista Eletrônica de Enfermagem, 14(3), 483-493. 